\title{
DETERMINANTES DO NASCIMENTO DE EMPRESAS NO RIO GRANDE DO SUL: UM MODELO DE DADOS EM PAINEL ESPACIAL, 2007-2013
}

\author{
Carlos Hernán Rodas Céspedes * \\ Adelar Fochezatto ${ }^{\dagger}$
}

\begin{abstract}
Resumo
O objetivo deste artigo é analisar o nascimento de empresas nos municípios do Rio Grande do Sul no período entre 2007 e 2013. Para isso, utilizam-se procedimentos da análise exploratória de dados espaciais e regressão em painel espacial. Os resultados indicaram a existência de autocorrelação espacial do nascimento de empresas e a formação de alguns clusters de municípios com altos nascimentos de empresas. O modelo de autorregressão espacial (SAR) evidenciou o efeito transbordamento do nascimento de empresas e possibilitou a mensuração dos impactos diretos e indiretos das variáveis independentes sobre o nascimento de empresas.
\end{abstract}

Palavras-chave: nascimento de empresas, transbordamento espacial, painel espacial.

\begin{abstract}
The objective of this paper is to analyze the birth of companies in the cities of Rio Grande do Sul State between 2007 and 2013. For that, exploratory analysis of spatial data and the panel data regression were used. The results indicated the existence of spatial autocorrelation of the birth of companies and the formation of some clusters of the counties with high births of companies. The spatial autoregression (SAR) model showed the spillover effect of the birth of companies and made it possible to measure the direct and indirect impacts of the independent variables on the birth of companies.
\end{abstract}

Keywords: birth of companies, spatial spillover, spatial panel.

JEL classification: JEL: C23, R11.

DOI: http://dx.doi .org/10.11606/1980-5330/ea142259

\footnotetext{
* Professor da UNIPAMPA. Doutor em Economia do Desenvolvimento no PPGE/PUCRS. E-mail: carloshrodasc@gmail.com.

${ }^{\dagger}$ Doutor em Economia. Professor Titular da PUCRS. Pesquisador do CNPq. E-mail: adelar@pucrs.br
} 


\section{Introdução}

O nascimento de empresas não está distribuído de forma uniforme ao longo de todo o espaço geográfico de um país, região ou estado. É provável que alguns espaços geográficos apresentem determinadas características que os tornem mais atrativos para o início de uma atividade produtiva que outros. Krugman (1991) considerou a concentração da atividade econômica como a característica mais notável da geografia econômica. Quando questionado sobre o que explica a distribuição assimétrica da atividade econômica, ele se referiu aos retornos crescentes de escala, não em termos de uma planta ou de uma firma, mas em termos espaciais.

Influenciado por essas ideias, McCANN (2013) afirma que a premissa básica da abordagem espacial é que a aglomeração da atividade econômica conduz a um aumento da produtividade. Essa premissa seria a razão pela qual os potenciais empreendedores buscam iniciar e instalar seus negócios no interior ou nas proximidades das aglomerações. Ou seja, se imaginarmos a configuração espacial das aglomerações, é possível perceber que as externalidades associadas a elas podem exercer o seu efeito em favor, não somente da produtividade, mas também do nascimento de empresas na vizinhança.

Dessa maneira, dada a possibilidade das externalidades aparecerem em nível de empresas, e estas contribuírem em favor dos retornos crescentes de escala, resulta instigante averiguar se as externalidades em nível espacial também influenciam o nascimento de empresas, como o fizeram Audretsch \& Fritsch (1993) para o caso alemão. Reconhecer que tal resultado é possível, torna-se importante porque o nascimento de empresas, ao ser parte do processo de destruição criadora, acaba impulsionando a inovação e a produtividade dos recursos ${ }^{1}$ em nível espacial. Sendo assim, o objetivo deste estudo é analisar, a partir de uma perspectiva espacial, a relação de causalidade entre as principais características das aglomerações econômicas, da forma como são propostas por Audretsch \& Fritsch (1993) e Levratto \& Carré (2014), e o nascimento de empresas. O estudo está centrado no Estado do Rio Grande do Sul no período de 2007-2013. Para tal efeito, são utilizados procedimentos da Análise Exploratória de Dados Espaciais, com a finalidade de determinar a autocorrelação espacial do nascimento de empresas, assim como, a formação dos respectivos clusters no território do Rio Grande do Sul. Para identificar os efeitos de transbordamento espacial, são utilizados o método de dados de painel espacial e dois de seus modelos mais representativos. Assim, pretende-se avaliar se o nascimento de empresas é caracterizado por um processo de autocorrelação espacial e também se as relações entre o nascimento de empresas e as covariáveis locais estão sujeitas ao denominado efeito vizinhança, tal qual o manifesta Levratto \& Carré (2014).

Na próxima seção, apresenta-se a revisão da literatura sobre o assunto; a seguir, na terceira seção, se expõem as variáveis, os dados e a metodologia utilizada; na quarta seção, são apontados os resultados do estudo; e, finalmente, apresentam-se as conclusões.

\footnotetext{
${ }^{1}$ Segundo estudo da OCED, citado por Lopez-Garcia \& Puente (2006), a demografia de empresas, por meio da rotatividade, eleva a produtividade entre $20 \%$ a $30 \%$.
} 


\section{Revisão Bibliográfica}

\subsection{Aglomerações, Externalidades e Nascimento de Empresas}

$\mathrm{Na}$ literatura internacional, são encontrados trabalhos que procuram indagar quais são os fatores e de que maneira eles influenciam na localização do nascimento de novas empresas. Nos trabalhos de Audretsch \& Fritsch (1993), Lee et al. (2004), Fritsch (2011), Ross et al. (2015) e Levratto \& Carré (2014), o destaque é conferido ao papel das aglomerações, o empreendedorismo e o espaço geográfico.

No Brasil, pode se destacar o trabalho de Rezende et al. (2012) em que procuram explicar a localização espacial da indústria de transformação, dando ênfase ao papel das aglomerações. Para o Rio Grande do Sul, os estudos mais destacados são os de Canever et al. (2011), Menezes (2011) e Carraro \& Canever (2012). Estes analisam a dinâmica do nascimento de empresas, salientando o papel do empreendedorismo, verificando a existência de clusters de novas empresas e o seu impacto sobre o crescimento econômico.

Um dos trabalhos que reconheceram a importância do espaço geográfico nas decisões dos agentes é o estudo de Audretsch \& Fritsch (1993). Neste, resgatam-se as características subjacentes à concentração espacial da produção que Krugman notabilizou na sua Nova Geografia Econômica, com o objetivo de explicar o nascimento de empresas para o caso alemão ${ }^{2}$.

Nesse estudo, são valorizadas duas respostas que Krugman oferece quando questionado a respeito do que ele considera mais destacável na geografia econômica e das causas que ele atribui à distribuição assimétrica da atividade econômica no espaço. Ele diz que a concentração da atividade econômica é a característica mais notável da geografia econômica e relaciona essa distribuição desigual da atividade econômica no espaço às diferenças de distribuição espacial dos retornos crescentes de escala e às correspondentes externalidades: “..., it is assumed externalities across firms and even industries that yields convexities in production" (Audretsch \& Fritsch (1993), p. 359).

Conforme Audretsch \& Fritsch (1993), a criação de empresas é mais intensa no interior ou nas proximidades das aglomerações produtivas distribuídas ao longo do espaço. Portanto, seguindo o seu raciocínio, é procedente vincular o nascimento de empresas com algumas características ou condições espaciais que possibilitam a ocorrência de spillovers $^{3}$, a saber: 1) o agrupamento de mercados de trabalho por habilidade ou especialidade laboral produtiva; 2) a provisão de insumos específicos e de baixo custo dirigidos para a indústria; e, 3) o conhecimento tecnológico disponível no âmbito do espaço geográfico.

Em relação ao primeiro, cabe mencionar que, assim como para o empreendedor resulta vantajoso iniciar um empreendimento produtivo em um local onde é possível contar com uma oferta de mão de obra com habilidades específicas, o mesmo ocorre com o trabalhador, que se desloca para locais onde sua mão de obra especializada é demandada com maior probabilidade. Ambos os agentes procuram aumentar seus retornos em espaços geográficos que

\footnotetext{
${ }^{2}$ De forma similar, Olejnik (2014) destaca a argumentação da Nova Geografia Econômica para explicar que o crescimento da produtividade espacial da União Europeia recebeu a influência das externalidades tecnológicas, bem como das condições socioeconômicas regionais, e do progresso técnico das regiões vizinhas.

${ }^{3}$ No entender de Doring \& Schnellenbach (2004), os spillovers conduzem a externalidades dinâmicas e a efeitos da aglomeração em uma dimensão geográfica.
} 
apresentam vantagens produtivas e promovem o crescimento. “...it is actually the interaction of increasing returns and uncertainty that bestows advantages to the pooling of labor markets associated with agglomerations" (Audretsch \& Fritsch (1993), p. 360).

Além disso, a aglomeração torna possível a oferta diversificada de insumos e preços competitivos por parte de empresas localizadas no interior ou na vizinhança da mesma. Portanto, entende-se que potenciais empreendedores procuram instalar os seus negócios em espaços onde possam se beneficiar da presença de fornecedores de insumos específicos de qualidade e com preço competitivo. Quanto à terceira fonte de rendimentos crescentes, Audretsch \& Fritsch (1993) consideram que quem mais se beneficia dos spillovers tecnológicos espaciais são, principalmente, as empresas de menor porte localizadas nas aglomerações ou no seu entorno.

Seja qual for o tipo de spillover considerado, a sua manifestação pode ser verificada por meio dos impactos sobre a produtividade dos fatores ou, no caso particular deste trabalho, por meio da taxa de nascimento de empresas. Assume-se que no caso específico do transbordamento do conhecimento ${ }^{4}$, este se dissemina e se torna disponível de forma instantânea para todos os agentes ${ }^{5}$. Mas, o seu impacto pode ficar comprometido por causa da distância geográfica que separa o potencial beneficiário do local de origem do spillover.

Com a finalidade de ter uma noção mais aproximada da dimensão da dependência espacial, Plummer (2010) explora o efeito do espaço sobre o empreendedorismo por meio dos procedimentos da Análise Exploratória de Dados Espaciais e de técnicas econométricas que consideram a dependência espacial. Ele lança o alerta para o problema da não consideração da dependência espacial em modelos econométricos que estimam os determinantes do nascimento de empresas. Nesse caso, os estimadores resultarão viesados, inconsistentes e ineficientes, dada a tendência da atividade empreendedora formar clusters espaciais. (Plummer (2010), p. 171).

O resultado da autocorrelação espacial é importante ao reportar informação acerca da correlação espacial de uma variável com ela própria. Provavelmente, as regiões vizinhas de centros econômicos dinâmicos, representados por clusters de inteligência, inovação, etc. repercutem de forma mais intensa o efeito das externalidades decorrentes da proximidade espacial. Caso a autocorrelação seja positiva, é provável que, por exemplo, a criação de novas empresas nas proximidades de um cluster de inovação seja impulsionada pela atividade empreendedora nessas aglomerações em atividades semelhantes ou complementares.

Reynolds \& Maki (1992) sinalizam que variáveis agregadas como a taxa de desemprego, a densidade de população e a disponibilidade de financiamento são importantes para explicar a variação, em nível regional, da taxa de nascimento de novas empresas. C \& Acs (2002) consideram que a concentração industrial, o crescimento da renda, o crescimento populacional e o capital humano se relacionam fortemente com o nascimento de empresas. Kirchhoff, citado por Lee (2001), indica que a pesquisa acadêmica e os gastos com o de-

\footnotetext{
${ }^{4}$ Segundo Doring \& Schnellenbach (2004), um tipo particular de externalidade é o resultado do spillover de conhecimento o qual se constitui em uma fonte de retornos de escala.

${ }^{5} \mathrm{~A}$ outra possibilidade é assumir que o spillover do conhecimento não existe, uma vez que é compreendido enquanto bem privado, restrito a um grupo de agentes (Doring \& Schnellenbach (2004), p. 8).
} 
senvolvimento estão associados de forma significativa com a taxa de formação de novas empresas.

O estudo de Levratto \& Carré (2014) destaca a questão do espaço geográfico enquanto variável explicativa do nascimento de empresas, uma vez que o território congrega recursos humanos, financeiros, organizacionais e materiais que afetam de forma direta a formação de negócios. Chamam a atenção para a estrutura industrial do território, assim como para a taxa de desemprego, a densidade populacional e o espírito empreendedor enquanto determinantes do nascimento de empresas. Citam as contribuições de Krugman (1991) e de Aghion \& Howitt (1998) a respeito da influência da Nova Geografia Econômica e das teorias do crescimento endógeno nos estudos dedicados a explorar os motivos que levam os empreendedores a escolherem um determinado local para iniciar um negócio. Segundo estas teorias, as aglomerações espaciais podem criar vantagens locacionais em termos de spillovers e cooperação entre firmas. (Audia \& Sorenson (2000) apud Levratto \& Carré (2014), p. 3).

Ao admitir a importância do espaço na decisão para empreender um novo negócio e dar resposta à questão relacionada com a intensidade em que a taxa de nascimento de empresas se vê afetada pelas características específicas de regiões adjacentes, Levratto \& Carré (2014) utilizam a técnica de dados de painel espacial para estimar a dependência espacial e a influência do empreendedorismo sobre a criação de empresas em áreas vizinhas. Os modelos utilizados postulam o nascimento de empresas como resultado de um processo espacial e autorregressivo e/ou de um processo espacial autorregressivo do termo do erro (Levratto \& Carré (2014), p. 3). O seu trabalho complementa a proposta sugerida por Audretsch \& Fritsch (1993) a respeito do nascimento de empresas e do impacto das aglomerações distribuídas no espaço. De forma implícita e indireta, o estudo evidencia o efeito vizinhança em favor da inovação, da competição, da produtividade e do emprego de qualidade ${ }^{6}$.

Levratto \& Carré (2014) adotam a estrutura sugerida por Keeble et al. (1993) e Johnson \& Parker (1996) para fazer referência às três categorias de fatores que tornam os espaços geográficos (regiões) mais ou menos empreendedores: os fatores locais, que estão relacionados com o tamanho de mercado e a demanda potencial; os fatores relacionados com as características atrativas do local; e os fatores relacionados ao ambiente de negócios.

Em relação à primeira categoria, os autores supracitados consideram que a abertura de novas empresas é influenciada pela demanda de mercado, a qual, por sua vez, é função do número de habitantes do local, assim como, da dimensão da renda média e do acesso ao crédito local. Na segunda categoria, estão os fatores de aglomeração de empresas. Os autores afirmam que os espaços geográficos com maiores taxas de entrada de empresas exercem uma "força magnética" sobre os potenciais empreendedores. Em vista disso, acredita-se que locais com maiores taxas de crescimento populacional tendem a se tornar mais atrativas para abrir uma empresa quando comparadas com locais cujas populações são menores e/ou com taxas declinantes de crescimento populacional (Levratto (2015), p. 169).

Quando o ambiente econômico é desfavorável, por causa, por exemplo, de uma recessão geral da atividade econômica, o desemprego aumenta e as

\footnotetext{
${ }^{6} \mathrm{O}$ trabalho de Audretsch et al. (2008) explora o efeito do desemprego sobre o autoemprego quando novas empresas formadas por trabalhadores ex-empregados devem mostrar maior produtividade ao abrir um negócio próprio.
} 
oportunidades de trabalho diminuem. Nesse contexto, pode ocorrer que a taxa de nascimento de empresas aumente, situação conhecida como de empreendedorismo por necessidade. Em caso de expansão econômica diminui o desemprego e, por isso, o aumento da abertura de novas empresas se deve a melhorias nas oportunidades de negócios (Levratto (2015), p. 169).

Levratto \& Carré (2014) consideram que o ambiente de negócios também se relaciona com o funcionamento das instituições. Em tese, um ambiente de mercado livre de distorções influencia de forma positiva a abertura de novas empresas. Já os ambientes caracterizados pela presença de economias de escala e empresas de tamanho grande, podem obstaculizar a entrada de novas empresas.

De forma semelhante ao apontado por Audretsch \& Fritsch (1993), Levratto \& Carré (2014) também consideram os efeitos em favor do nascimento de novas empresas decorrentes das aglomerações e das externalidades originadas na urbanização. Segundo Plummer (2010) (apud Levratto \& Carré (2014), p. 6) há motivações teóricas para esperar que a dependência espacial de novas firmas seja maior que a dependência de firmas mais velhas.

O estudo de Ross et al. (2015) explora que alguns fatores relacionados com a demanda, oferta e cultura explicam a variação no número de empresas nas regiões da Escócia. Entre os primeiros, destacam-se o crescimento da população e os respectivos níveis de renda, a começar pelo valor do salário. Também ponderam o fator espacial ao encontrar evidências de que as diferenças espaciais na demanda por bens e serviços influenciam a demanda por empreendedorismo (Ross et al. (2015), p. 674).

Quanto aos fatores de oferta, os autores supracitados aceitam o impacto negativo do desemprego sobre a taxa de atividade empreendedora, uma vez que, ao inibir a demanda de mercado por bens e serviços, coloca em risco a renda esperada e a expectativa de lucros. Da mesma forma, indicam que tanto o capital humano, associado à aquisição de conhecimento, quanto a riqueza e/ou o acesso ao financiamento, influenciam a oferta de atividade empreendedora.

Em relação ao primeiro aspecto levantado acima, cabem alguns apontamentos. Tal relação retrata a realidade de países ou regiões desenvolvidas com taxas de desemprego baixas em que tende a prevalecer o empreendedorismo por oportunidade. Já no caso de países ou regiões menos desenvolvidos com taxas de desemprego elevadas, a realidade é diferente, nestes, as oportunidades de trabalho são escassas e as pessoas desempregadas tentam obter renda por meio do trabalho autônomo ou da abertura de empresas, principalmente empresas individuais.

No caso do Brasil, alguns estudos mostraram uma relação positiva entre a taxa de desemprego e a abertura de empresas, enquanto que outros indicaram uma relação negativa. Esses resultados contraditórios podem ser explicados pela amostra utilizada, isto é, se foram ou não consideradas as MEIs (microempresas individuais), e/ou pelo período específico do estudo. Alguns relatórios do SEBRAE apontam a existência de uma relação direta entre o aumento do desemprego e o aumento da formação de empresas. Para o período recente no Brasil, caracterizado por altas taxas de desemprego, um desses informes destaca o seguinte: entre meados de 2013 e 2016 foram criadas mais de 11 milhões de novas empresas; o percentual de novas empresas por necessidade passou de 29\% em 2014 para 43\% em 2015; e, das 955,3 mil empresas abertas entre janeiro e maio de 2016, 79,2\% corresponderam a microempreendedores individuais (SEBRAE 2017). 
Por outro lado, Menezes (2015) analisou os fatores que explicam a abertura de novas empresas no Brasil entre 2003 e 2008. Na amostra utilizada, não são mencionadas as empresas MEIs, e o autor utiliza um conjunto de variáveis explicativas entre as quais se destaca a taxa de desemprego defasada em um período. Os resultados para essa variável se mostraram estatisticamente significativos, mas indicaram que uma redução da taxa de desemprego está associada a um aumento da taxa de abertura de empresas.

Em relação aos fatores de aglomeração, apontam que uma parte das atividades produtivas está clusterizada no espaço, e que a criação de empresas é influenciada pelas externalidades pecuniárias e não pecuniárias originadas nas aglomerações. Por exemplo, o acesso à mão de obra qualificada, a fornecedores de insumos especializados e aos spillovers do conhecimento, permitem baixos custos de transação e de transporte, bem como, retornos crescentes que sustentam a competitividade das empresas (Ross et al. (2015), p. 676). Assim, as economias de aglomeração provavelmente incidem de forma positiva nas taxas de empreendedorismo.

Ross et al. (2015) consideram que o nível de competição nos mercados não deveria ser restrito ao âmbito das empresas privadas, mas também ao âmbito das relações entre as empresas privadas e o setor público. Os autores afirmam que um alto número de empregados no setor público ${ }^{7}$, associado à estabilidade no emprego, diminui o contingente de pessoas com as habilidades requeridas para iniciar um pequeno negócio na esfera privada. Da mesma maneira, um setor público inchado provavelmente desloque as funções do setor privado (Ross et al. (2015), p. 677). Dessa maneira, esses autores parecem assumir de forma implícita que, em determinadas condições, a produtividade dos funcionários públicos não corresponderia à dos empreendedores da iniciativa privada e que um setor público grande interferiria de forma ineficiente nas competências do setor privado.

A questão cultural também é objeto de análise, uma vez que esta parece definir a intensidade ou a atitude empreendedora dos agentes de uma região. No modelo proposto por Ross et al. (2015) uma proporção elevada de pequenas empresas com menos de cinquenta empregados em relação ao total é um indicador da cultura empreendedora regional, uma vez que estimulam o crescimento das empresas por meio de uma rede de contatos que lhes permitem o intercâmbio de informações relevantes para a vida dos negócios. Essa intensidade empreendedora pode, segundo esses autores, aumentar a taxa de nascimento de empresas (Ross et al. (2015), p. 677).

\subsection{Considerações Operacionais}

Uma das contribuições importantes do trabalho de Audretsch e Fritsch é sugerir de que maneira os conceitos relacionados com os tipos de spillover se tornam operacionalizáveis. Quando se faz referência ao fato da oferta de infraestrutura e dos serviços serem mais desenvolvidos em regiões densamente populosas, implicitamente se sugere que é maior a probabilidade de se encontrar, nesses espaços, mercados de trabalho especializados e indústrias fornecedoras de insumos específicos de qualidade. Assim, afirmam que, em tese, a taxa de nascimento de empresas está relacionada diretamente com os locais

\footnotetext{
${ }^{7}$ No caso escocês, (Ross et al. (2015), p. 677) indicam que o percentual de trabalhadores no setor público é $28,3 \%$.
} 
onde a densidade populacional, o crescimento populacional e o produto per capita são maiores (Audretsch \& Fritsch 1993).

Além dessas variáveis populacionais, a taxa de desemprego também é sugerida, mas o seu tratamento, como já foi visto, é complexo, uma vez que, por um lado, uma elevada taxa de desemprego regional é equivalente a um menor crescimento econômico e baixas chances em favor do nascimento de empresas. Por outro lado, a disponibilidade de recursos em favor de novas empresas tenderia a aumentar na medida em que as taxas de desemprego forem maiores, tornando esse comportamento atrativo para novos empreendedores.

A relação entre a qualidade da mão de obra e a taxa de nascimento de empresas também se espera que seja positiva no sentido da abertura de novas empresas ficarem localizadas em regiões onde a mão de obra é mais qualificada. No seu entendimento, tal expectativa está relacionada com as externalidades originadas nos grupos de mercados de trabalho especializados e nos spillovers da informação que ocorrem onde a mão de obra é mais qualificada. Todavia, é provável que a mão de obra qualificada esteja relacionada com a presença de instituições de ensino superior ou instituições de ensino profissionalizantes de nível médio.

Sugere-se que se tenha em consideração o tamanho médio dos estabelecimentos, não por guardar relação com algum tipo de spillover capaz de tornar maior a taxa de nascimento de empresas, senão porque, no modelo proposto por Audretsch \& Fritsch (1993), ela é uma variável de controle do viés inerente à taxa de nascimento quando esta é mensurada a partir da abordagem ecológica ${ }^{8}$. Nesse caso, observa-se que, em regiões onde o tamanho médio dos estabelecimentos é maior, tende-se a superestimar o nascimento de empresas para um número dado de trabalhadores. Já quando a abordagem é a do mercado do trabalho, assume-se que quem inicia um novo empreendimento é alguém que está no mercado de trabalhado, portanto, é de esperar que a relação entre o tamanho médio do estabelecimento e a taxa de nascimento de novas empresas seja negativa, uma vez que, em regiões onde o número de estabelecimentos de tamanho pequeno é relativamente maior, para um número dado de trabalhadores, existirá uma probabilidade maior de que um trabalhador pertencente ao estabelecimento menor inicie um novo negócio.

Por seu lado, Levratto \& Carré (2014) consideram entre as variáveis explicativas a intensidade empreendedora do espaço geográfico entendida como a relação entre o número de novas empresas estabelecidas nessa região e o número total de empresas operando na mesma região. Especial atenção é dada ao efeito de aglomeração, que são economias externas que as firmas usufruem pelo fato de estarem localizadas próximas de outras firmas. Para calcular o efeito da aglomeração, utiliza-se a relação entre o número de trabalhadores em uma determinada área dividida pela respectiva área medida em quilômetros quadrados. Como medida alternativa, também pode ser considerado o número de trabalhadores na indústria manufatureira comparada com o total de empregados. Se o sinal é positivo, então se conclui que novas empresas industriais tendem a se localizar em áreas industriais, enquanto que, se o sinal é negativo, o ingresso de empresas é complementar às atividades industriais.

\footnotetext{
${ }^{8} \mathrm{~A}$ abordagem ecológica mensura o nascimento de empresas a partir da fração entre a variação de novas empresas e o número total de empresas na região. A abordagem do mercado de trabalho opta por dividir a variação de empresas pelo número da força de trabalho em uma região.
} 


\section{Metodologia}

Este trabalho recorre à Análise Exploratória dos Dados com a finalidade de verificar a dependência espacial da variável "nascimento de empresas". Em primeiro lugar, utiliza-se o Índice de Moran, que é uma medida de autocorrelação espacial, e o Índice Local de Associação Espacial, LISA, que possibilita a identificação de clusters de municípios segundo o nascimento de empresas. $\mathrm{Na}$ sequência, procede-se a estimar o modelo de painel espacial para explicar a taxa de entrada de empresas nos municípios do Rio Grande do Sul no período 2007-2013. As variáveis utilizadas no modelo estão na Tabela 1.

Os dados da variável nascimento de empresas são únicos e identificáveis para cada empresa e foram obtidos junto à base de microdados do Ministério do Trabalho e Emprego (MTE). Com esses dados, é possível calcular exatamente o número de novas empresas por ano/município bem como o número de empresas que fecharam no período. Com os dados abertos é possível conhecer apenas o saldo líquido de empresas por ano/município. Além disso, por meio do Cadastro Nacional da Pessoa Jurídica (CNPJ), é possível acompanhar as empresas ao longo do tempo e avaliar, por exemplo, a mortalidade e a sobrevivência de empresas classificadas por setores produtivos, regiões, tamanho ou outras características de interesse. Os dados das variáveis independentes foram obtidos junto ao IBGE, Fundação de Economia e Estatística (FEE) ao MTE (RAIS). A Tabela 2 apresenta as estatísticas descritivas das variáveis utilizadas.

Observa-se que no Rio Grande do Sul em média ocorre o nascimento de 4,8 novas empresas a cada mil pessoas da força de trabalho por ano. Possui uma densidade demográfica média de 43,9 pessoas por quilômetro quadrado, um produto real per capita de $\mathrm{R} \$ 8.311,9$ (a preços de 2007) e uma participação média da indústria no valor adicionado bruto de $15 \%$. Em relação às variáveis do mercado de trabalho, em média $76 \%$ dos empregados formais são classificados como não qualificados, $20 \%$ da população ativa está ocupada em algum emprego formal, a qual tem aumentado em torno de $5 \%$ ao ano no período analisado. Em relação à população, percebe-se que sua taxa de crescimento em períodos de três anos tem sido muito baixa, próxima de zero $(0,07 \%)$. Além disso, no período analisado em média as empresas empregaram 8,6 trabalhadores. Por fim, no período havia 5,8 alunos matriculados no ensino superior a cada mil pessoas.

As informações oriundas da RAIS referem-se aos empregos e empresas formais. Então, é possível que esteja usando valores superestimados para o nascimento de novas empresas (NascTrab), já que o número de trabalhadores está no denominador; e valores subestimados para tamanho médio dos estabelecimentos (TamEmp), emprego não qualificado (EmpNQual) e população ocupada em relação à população economicamente ativa (PocupPEA, VPocupPEA). Além disso, é preciso considerar que pode haver aumento ou diminuição da informalidade de acordo com o ciclo econômico, diminuindo em momentos de expansão e aumentando em momentos de crise.

Para avaliar a autocorrelação espacial do nascimento de empresas, foi utilizado índice I de Moran global. Este é aplicado nos resíduos das observações de corte transversal, sendo que o seu resultado está definido no intervalo entre $-1 \mathrm{e}+1$. Os valores positivos indicam a presença de correlação espacial positiva do nascimento de empresas entre os municípios. Isso significa que se houver alto (baixo) nascimento de novas empresas em um município, há tam- 
Tabela 1: Relação de variáveis e a forma de sua obtenção

\begin{tabular}{|c|c|c|c|}
\hline Variáveis & Sigla & Cálculo utilizado para sua obtenção & Fonte \\
\hline $\begin{array}{l}\text { Nascimento de empre- } \\
\text { sas }\end{array}$ & NascTrab & $\begin{array}{l}\text { Fração entre o número de empresas criadas no ano vigente e a } \\
\text { população economicamente ativa dos municípios dividida por } \\
1000 .\end{array}$ & $\begin{array}{l}\text { RAIS }^{*} \\
\text { IBGE }\end{array}$ \\
\hline $\begin{array}{l}\text { Densidade populacio- } \\
\text { nal }\end{array}$ & DenPopr & $\begin{array}{l}\text { Fração entre a população do município e a sua extensão territo- } \\
\text { rial (raiz quadrada). }\end{array}$ & IBGE \\
\hline $\begin{array}{l}\text { Emprego não qualifi- } \\
\text { cado }\end{array}$ & EmpNQual & $\begin{array}{l}\text { Fração entre o emprego não qualificado do município e o número } \\
\text { total de pessoas empregadas no ano vigente }\left(^{*}\right) \text {. }\end{array}$ & RAIS \\
\hline $\begin{array}{l}\text { Produto Interno Bruto } \\
\text { per capita }\end{array}$ & PIBpcr & $\begin{array}{l}\text { Fração entre o produto interno bruto real (preços de 2007) e a } \\
\text { população. }\end{array}$ & IBGE \\
\hline $\begin{array}{l}\text { População ocupada em } \\
\text { relação à população } \\
\text { economicamente ativa }\end{array}$ & PocupPEA & $\begin{array}{l}\text { Fração entre a população ocupada e a população economica- } \\
\text { mente ativa do município no ano corrente. }\end{array}$ & $\begin{array}{l}\text { RAIS } \\
\text { IBGE }\end{array}$ \\
\hline $\begin{array}{l}\text { Variação da população } \\
\text { ocupada em relação à } \\
\text { população economica- } \\
\text { mente ativa }\end{array}$ & VPocupPEA & $\begin{array}{l}\text { Variação anual da fração entre a população ocupada e a popula- } \\
\text { ção economicamente ativa. }\end{array}$ & $\begin{array}{l}\text { RAIS } \\
\text { IBGE }\end{array}$ \\
\hline $\begin{array}{l}\text { Variação da população } \\
\text { nos últimos três anos }\end{array}$ & Vpop3a & $\begin{array}{l}\text { Fração entre a população em um determinado ano e a população } \\
\text { de três anos antes. }\end{array}$ & IBGE \\
\hline $\begin{array}{l}\text { Tamanho médio dos es- } \\
\text { tabelecimentos por mu- } \\
\text { nicípio }\end{array}$ & TamEmp & $\begin{array}{l}\text { Fração entre o número de pessoas ocupadas no município e o } \\
\text { número total de empresas no ano corrente. }\end{array}$ & RAIS \\
\hline $\begin{array}{l}\text { Participação da indús- } \\
\text { tria na economia }\end{array}$ & IndVab & $\begin{array}{l}\text { Fração entre o valor adicionado da indústria e o valor adicionado } \\
\text { bruto total do município no ano corrente. }\end{array}$ & IBGE \\
\hline $\begin{array}{l}\text { Matrículas do ensino } \\
\text { superior }\end{array}$ & MatrESPop & $\begin{array}{l}\text { Fração entre o número de matrículas no ensino superior e a po- } \\
\text { pulação de } 18 \text { a } 24 \text { anos do município, dividida por mil. }\end{array}$ & $\begin{array}{l}\text { INEP } \\
\text { IBGE }\end{array}$ \\
\hline
\end{tabular}

Fonte: Elaboração própria.

Nota: $\left.{ }^{*}\right)$ Para o cálculo do emprego não qualificado se excluem do total dos empregos os seguintes: membros superiores do poder

público, dirigentes de organizações de interesse público, profissionais das ciências e das artes e os técnicos de nível médio. 
Tabela 2: Estatísticas descritivas das variáveis utilizadas

\begin{tabular}{l|c|c|c|c}
\hline Variáveis & Média & Desvio-padrão & Valor Mínimo & Valor Máximo \\
\hline Nascstrab & 4,8084 & 2,2169 & 0,0000 & 15,7140 \\
DenPopr & 6,6302 & 6,7897 & 1,2129 & 55,8632 \\
EmpNQual & 0,7626 & 0,0893 & 0,3024 & 0,9693 \\
PIBpcr & 8,3119 & 6,3659 & 2,4535 & 116,2167 \\
PocupPEA & 0,2023 & 0,1244 & 0,0197 & 1,1810 \\
VPocupPEA & 1,0507 & 0,1514 & 0,2853 & 4,0858 \\
Vpop3a & 1,0007 & 0,0380 & 0,8595 & 1,2742 \\
TamEmp & 8,6070 & 4,0806 & 2,7166 & 46,2380 \\
IndVab & 0,1518 & 0,1645 & 0,0091 & 0,9196 \\
MatrESPop & 5,8027 & 18,3962 & 0,0000 & 224,9487 \\
\hline
\end{tabular}

Fonte: Elaboração própria a partir dos dados da FEE e da RAIS/MTE.

Obs.: Os valores das estatísticas referem-se aos dados em pooled (3472 observações; $1: 1-496: 7)$

bém alto (baixo) nascimento de empresas nos municípios vizinhos. Há, portanto, efeitos de transbordamento espacial. Por outro lado, valores negativos indicam correlação espacial negativa. Nesse caso, um alto (baixo) nascimento de empresas em um município é acompanhado por baixo (alto) nascimento de empresas nos municípios vizinhos. Nesse caso, é possível que exista rivalidade ou competição entre os municípios, isto é, o maior nascimento de empresas em um município acaba afetando negativamente o nascimento de empresas em outro município vizinho.

O índice I de Moran é definido da seguinte maneira:

$$
I=\frac{N}{\sum_{i} \sum_{j} w_{i j}} \frac{\sum_{i} \sum_{j} w_{i j}\left(Y_{i}-\bar{Y}\right)\left(Y_{j}-\bar{Y}\right)}{\sum_{i}\left(Y_{i}-\bar{Y}\right)^{2}}
$$

em que: $N$ é o número de observações; $Y$ é a variável de interesse; $\bar{Y}$ é a média da variável de interesse; os subíndices $i$ e $j$ referem-se a duas observações (dois municípios) vizinhos; e $w_{i j}$ é um elemento da matriz de pesos ${ }^{9}$ espaciais, segundo o critério de contiguidade, distância ou distância econômica. Tal matriz, de acordo com os critérios de contiguidade, determina o grau de conexão entre os municípios.

De forma complementar, é possível estabelecer, por meio do indicador de associação espacial local, LISA $\left(I_{i}\right)$, a possibilidade de existirem municípios associados espacialmente segundo a variável de interesse. Enquanto o I de Moran procura sintetizar a dependência espacial em toda a região estudada, o LISA calcula a associação espacial em locais específicos (subgrupos de observações). A sua definição é a seguinte:

$$
\begin{gathered}
I_{i}=\frac{\left(Y_{i}-\bar{Y}\right)}{m_{2}} \sum_{j} w_{i j}\left(Y_{j}-\bar{Y}\right) \\
\text { emque }: m_{2}=\frac{\sum_{i}\left(Y_{i}-\bar{Y}\right)^{2}}{N}
\end{gathered}
$$

\footnotetext{
${ }^{9}$ Para mais detalhes sobre os tipos de matrizes de pesos, ver Almeida (2012).
} 
Com a determinação do indicador LISA, obtém-se informações que permitem identificar associações de municípios que se encontram espacialmente correlacionados. Esse indicador possibilita a visualização de clusters de municípios por meio de mapas de associação espacial.

Aceita a possibilidade de existir autocorrelação espacial da variável de interesse e a presença de clusters de municípios segundo a correlação positiva da respectiva variável, procede-se com a formulação do modelo econométrico específico. Com base nas variáveis propostas no modelo de Audretsch \& Fritsch (1993), e adicionando a influência do ensino superior e o peso do setor industrial sobre o nascimento de empresas, formula-se o modelo de painel espacial com a finalidade de testar a hipótese de que o nascimento de empresas em uma região depende: dos efeitos espaciais da própria variável; das variáveis relacionadas aos spillovers espaciais levantados por Krugman (1991) (apud Audretsch \& Fritsch (1993), p. 360); da educação superior da população do município, representada pelas matrículas no ensino superior (indicador de presença de universidades); e da influência das aglomerações produtivas, utilizando como proxy o peso das atividades industriais nesses espaços.

A representação do modelo para o nascimento de empresas assume a seguinte forma genérica:

$$
Y_{t}=f\left(X_{t}\right)
$$

em que: $Y_{t}$ representa o nascimento de empresas ou a taxa de entrada de empresas segundo a abordagem do mercado de trabalho (NascTrab); e $X_{t}$ representa um vetor de variáveis independentes, definidas na Tabela 1.

O cálculo da variável dependente nascimento de empresas (NascTrab) segue a abordagem do mercado de trabalho, segundo o qual se padroniza a variação de novos estabelecimentos em relação ao tamanho da força de trabalho. O apelo por esse método está relacionado com a teoria da escolha empreendedora proposta por Evans \& Jovanovic (1989), isto é, cada estabelecimento novo é conduzido por uma pessoa que se encontra inserido no mercado do trabalho. Além disso, em tese, a maioria dos novos empreendimentos que iniciam suas operações é de porte pequeno e é comandada por pessoas que estão ou estiveram inseridas no mercado do trabalho. A mensuração da entrada de empresas foi realizada utilizando-se os microdados da RAIS e os dados das pessoas inseridas no mercado do trabalho em cada município foram obtidos junto à FEE.

Para verificar a hipótese anteriormente proposta, opta-se pelo método de estimação de dados em painel espacial com base nas contribuições de Almeida (2012), Almeida et al. (2014) e Golgher (2015). As estimações foram realizadas com o programa livre R, utilizando Arbia (2014) como referência. Os dados em painel apresentam, na dimensão transversal, um total de 496 observações correspondentes aos municípios do Rio Grande do Sul e, na dimensão temporal, um total de sete anos, 2007-2013, assim se pretende captar as variações nas variáveis ocorridas tanto no espaço (em nível dos municípios) como no tempo.

A estrutura do modelo de dados em painel está representada pela seguinte expressão: 


$$
Y_{i t}=X_{i t} \beta+\alpha_{i}+\delta_{t}+e_{i t}
$$

em que: $i$ refere-se a cada uma das observações (municípios); $t$ refere-se ao tempo (2007-2013); $Y_{i t}$ é o vetor da variável dependente; $X_{i t}$ é o vetor das variáveis explicativas; $\beta$ são os coeficientes estimados para cada variável explicativa; $\alpha_{i}$ é o termo que captura a heterogeneidade não observada entre as observações (invariante no tempo); $\delta_{t}$ captura as especificidades temporais (invariantes entre as observações); $e_{i t}$ é o termo de erro i.i.d. (idêntico e independentemente distribuído) com média zero e variância constante.

Esse modelo, inspirado em Audretsch \& Fritsch (1993), sugere determinadas expectativas comportamentais do nascimento de empresas em função das variáveis independentes, conforme a Tabela 3. Complementarmente àquele modelo, o estudo incorpora a variável dependente defasada espacialmente assim, como os choques aleatórios defasados espacialmente. Além disso, o modelo proposto neste trabalho é um painel espacial, enquanto que o de $\mathrm{Au}$ dretsch \& Fritsch (1993) trata-se de um modelo de cross-section não espacial.

Alguns trabalhos aplicados utilizando modelos de painel espacial sugerem uma sequência de passos em direção à sua estimação, a exemplo de Almeida et al. (2014). Assim, depois da estimação do modelo (4), procede-se à avaliação dos componentes não observados por meio do teste de Breusch-Pagan, cuja hipótese nula é de que a variância dos resíduos devido aos efeitos individuais é igual a zero. Se os efeitos não observados não são importantes, opta-se pelo modelo pooled, estimado por MQO, caso contrário, procede-se a indagar os efeitos fixos ou aleatórios do modelo.

No caso do modelo com efeitos fixos, assume-se que ele captura as diferenças não observadas entre os municípios cujos efeitos originam-se em variáveis omitidas que variam entre municípios ao longo do tempo. Pode ocorrer que algumas variáveis omitidas sejam constantes no tempo, mas variáveis entre indivíduos, enquanto que, outras resultem variáveis no tempo e constantes entre indivíduos. Nesses casos, teríamos, na expressão acima, a especificação dos efeitos fixos municipais e temporais por meio de $\alpha_{i t}$.

No caso da presença de efeitos aleatórios, a ordenada na origem $\alpha_{i t}$ é uma variável aleatória e não é correlacionada com as variáveis explicativas. Nesse caso, agrupam-se os termos não observados junto do erro aleatório $v_{i t}=e_{i t}+$ $w_{i}$, assumindo que o efeito aleatório não observado $w i$ depende apenas do município $i$.

Após a estimação dos modelos de efeitos fixo e aleatório, sem dependência espacial, aplica-se o teste de Hausman para optar por um deles.

Em caso de se confirmar a dependência espacial, resta estimar o modelo que melhor representa os dados. A forma mais geral da representação sugerida pelo método de painel espacial é a seguinte:

$$
\begin{gathered}
Y_{i t}=\rho W Y_{i t}+X_{i t} \beta+W X_{i t} \tau+\xi_{i t} \\
\xi_{i t}=\lambda W \xi_{i t}+\varepsilon_{i t}
\end{gathered}
$$

No caso do Modelo (5), diferentemente do Modelo (4), os coeficientes $\rho$ (escalar), $\lambda$ (escalar) e $\tau$ (vetor) referem-se aos impactos espaciais decorren- 
Tabela 3: Variáveis explicativas e seus efeitos esperados sobre o nascimento de empresas (NascTrab) nos municípios do Rio Grande do Sul, 2007-2013

\begin{tabular}{c|l|c}
\hline Sigla & \multicolumn{1}{c|}{ Variável } & $\begin{array}{c}\text { Efeito Esperado } \\
(+\mathbf{o u}-)\end{array}$ \\
\hline DenPopr & Densidade populacional & + \\
\hline EmpNQual & Emprego não qualificado & - \\
\hline PIBpcr & Variação do PIB per capita & + \\
\hline PocupPEA & Taxa de emprego & + \\
\hline VPocupPEA & Variação na taxa de emprego & - \\
\hline Vpop3a & $\begin{array}{l}\text { Variação na população nos últimos } \\
\text { três anos }\end{array}$ & + \\
\hline TamEmp & Tamanho das empresas & + \\
\hline IndVab & Proporção da produção industrial & + \\
\hline MatrESPop & Matrículas no ensino superior & $\begin{array}{l}\text { Efeito transbordamento espacial do } \\
\text { nascimento de empresas em municí- } \\
\text { pios vizinhos }\end{array}$ \\
\hline$\lambda$ & $\begin{array}{l}\text { Efeito de choques aleatórios espaci- } \\
\text { almente defasados }\end{array}$ & + \\
\hline
\end{tabular}

Fonte: Elaboração própria.

tes de: a variável dependente espacialmente defasada $W Y_{i t}$; os erros espacialmente defasados, $W \xi_{i t}$; e, as variáveis independentes espacialmente defasadas; $W X_{i t}$. O $W$ representa a matriz quadrada de dimensão 496 x $496 \mathrm{e}$ refere-se à conexão entre os municípios do Rio Grande do Sul.

Com a especificação anterior, e impondo algumas restrições, são obtidos os dois modelos aqui pretendidos: o Modelo Autorregressivo Espacial, que considera somente a dependência da variável dependente (SAR), e o Modelo do Erro Espacial (SEM), o qual considera somente a dependência espacial dos erros. A especificação dos Modelos SAR e SEM é, respectivamente, a seguinte:

$$
\begin{gathered}
Y_{i t}=\rho W Y_{i t}+X_{i t} \beta+\xi_{i t} \\
Y_{i t}=X_{i t} \beta+\xi_{i t} \\
\xi_{i t}=\lambda W \xi_{i t}+\varepsilon_{i t}
\end{gathered}
$$

Comprovada a presença de dependência espacial, em geral a escolha de qual modelo espacial usar decorre da análise de testes estatísticos de multiplicadores de Lagrange (LM) aplicados aos resíduos do modelo clássico de mínimos quadrados ordinários. Esses testes servem para diagnosticar a natureza da dependência espacial. São eles: LM Lag, para verificar a presença de dependência espacial na variável endógena; LM Error, para verificar a presença de dependência espacial nos erros; RLM Lag (LM robusto), para verificar a presença de dependência espacial na variável endógena; e RLM Error (LM robusto), para verificar dependência espacial nos erros. Os dois últimos são aplicados apenas se os dois primeiros forem ambos significativos. Se os quatro forem significativos, então utiliza-se um modelo tipo SAC, que considera os dois tipos de dependência espacial. 
Em caso do modelo escolhido ser o SAR, Modelo (6), é possível determinar os efeitos diretos e indiretos das variáveis explicativas de modo a discriminar o denominado efeito transbordamento espacial ${ }^{10}$.

\section{Resultados}

\subsection{Análise Exploratória dos Dados}

A primeira questão é verificar a autocorrelação espacial do nascimento de empresas por meio do I de Moran bem como a presença dos clusters de municípios por meio do LISA. Como exposto anteriormente, o I de Moran positivo e significativo confirma que mais nascimentos de empresas em um município estão relacionados espacialmente com mais nascimentos de empresas em municípios vizinhos. É como se o que ocorresse em um município transbordasse para os municípios vizinhos. A correlação espacial pode ser negativa e ocorre, por exemplo, em disputa por mais recursos entre dois vizinhos cujo ganhador acaba prejudicando o rival, ou seja, na disputa por mais empreendedores, um dos municípios atrai todos os empreendedores inclusive os do município vizinho. Para calcular esse indicador, é preciso definir qual a matriz de pesos a ser usada. A Tabela 4 mostra os valores do Índice de Moran para várias matrizes de vizinhança espacial.

Como observado, destacam-se os valores do índice obtidos a partir da matriz de vizinhança 3 vizinhos, uma vez que, com ela, são gerados os maiores valores do Índice de Moran. O resultado não deixa de surpreender, porque se esperava que as matrizes Rainha ou Torre pudessem gerar maiores valores e se sobressair aos outros. Mas, o importante é constatar a existência da autocorrelação espacial, como pode ser verificado.

Tabela 4: Índice I de Moran e o grau de dependência espacial da variável NascTrab

\begin{tabular}{|c|c|c|c|c|c|c|}
\hline \multicolumn{7}{|c|}{ Matrizes de vizinhança ${ }^{* *}$} \\
\hline Ano & Queen & Rook & 3 Vizinhos & 4 Vizinhos & 5 Vizinhos & $67 \mathrm{~km}^{*}$ \\
\hline 2007 & 0,213 & 0,212 & 0,250 & 0,243 & 0,220 & 0,125 \\
\hline 2008 & 0,170 & 0,175 & 0,194 & 0,189 & 0,175 & 0,101 \\
\hline 2009 & 0,158 & 0,163 & 0,212 & 0,188 & 0,175 & 0,098 \\
\hline 2010 & 0,219 & 0,223 & 0,228 & 0,229 & 0,220 & 0,116 \\
\hline 2011 & 0,186 & 0,189 & 0,223 & 0,198 & 0,193 & 0,082 \\
\hline 2012 & 0,187 & 0,188 & 0,204 & 0,180 & 0,182 & 0,122 \\
\hline 2013 & 0,199 & 0,198 & 0,187 & 0,182 & 0,172 & 0,102 \\
\hline \multicolumn{7}{|c|}{$\begin{array}{l}\text { Fonte: Elaboração própria usando o programa GeoDa. } \\
\text { Nota: Todos os valores do Índice de Moran são estatisticamente significativos, com } \\
\text { pseudo p-value }=0,01 \text { (com } 99 \text { permutações); }{ }^{*} \text { ) Distância mínima para nenhum } \\
\text { município ficar ilhado (sem vizinhos). } \\
{ }^{* *} \text { As matrizes de vizinhança Rook (Torre) possuem fronteiras comuns a Leste, Oeste, } \\
\text { Norte e Sul. As matrizes Queen (Rainha), além das fronteiras comuns, incluem } \\
\text { também os vértices comuns. }\end{array}$} \\
\hline
\end{tabular}

Todavia, é possível gerar mapas para verificar a possibilidade de se encontrar grupos de municípios com as taxas de entrada de empresas distribuídos

\footnotetext{
${ }^{10}$ No segundo capítulo do livro de Golgher (2015), são apresentadas as deduções dos efeitos direto e indireto.
} 
de forma mais homogênea em cada grupo. Tal possibilidade se torna efetiva por meio do indicador local de associação espacial, LISA. Esse indicador permite visualizar no mapa do Rio Grande do Sul as regiões que concentram municípios correlacionados espacialmente segundo o nascimento de empresas. Essas regiões também podem ser reconhecidas com o nome de clusters de municípios.

Conforme pode ser visualizado na Figura 1, entre 2007 e 2013 houve uma retração na formação de clusters para o tipo de dependência espacial alto-alto. Por outro lado, houve um leve aumento na formação de clusters de dependência espacial do tipo baixo-baixo. Tais comportamentos podem ser reflexo do menor ritmo de crescimento da economia iniciado em 2010, que pode ter afetado negativamente os municípios.

É importante observar que não foram encontrados muitos municípios envolvidos em clusters espaciais. Os do tipo alto-alto predominaram na parte norte do Estado, que tem tido um dinamismo maior nas últimas décadas, especialmente na mesorregião Nordeste Rio-grandense, e os do tipo baixo-baixo predominaram na parte sul, especialmente na transição entre a mesorregião Metropolitana de Porto Alegre e mesorregião Sudeste Rio-grandense. No Nordeste do Estado está localizado o parque industrial de Caxias do Sul, que, pelo menos em parte, explica o bom desempenho dos municípios dessa região em termos de formação de novas empresas. No Sudeste Rio-grandense predomina uma economia primária baseada em pequenas propriedades, com solos ondulados e de baixa fertilidade.

Na região metropolitana de Porto Alegre, não se observou a formação de clusters, indicando heterogeneidade dos municípios que ali estão em termos de formação de novas empresas. Por outro lado, foram identificados clusters do tipo alto-alto na região do Litoral Norte do Estado. Esse resultado pode ser explicado pelo forte dinamismo populacional que essa região vem tendo nos últimos anos. Entre 2001 e 2016, essa região teve um aumento de mais de $40 \%$ em sua população enquanto que no Estado como um todo o crescimento foi de aproximadamente $9 \%$ e em Porto Alegre foi de $7 \%$.

No Apêndice B.1, está a lista de municípios que pertencentes a clusters do tipo alto-alto em 2007, em 2013 e nos dois anos. Foram dez os municípios que participaram de clusters nos dois anos. Destes, três se localizam na região do Litoral Norte, quatro na região da Serra e três se localizam na região da Produção (Passo Fundo). É fácil explicar esses resultados. No primeiro caso, explica-se pela presença de amenidades naturais (praia) e pelo forte adensamento populacional em curso. O segundo caso se explica pela influência do parque industrial de Caxias do Sul e do polo turístico de Gramado-Canela. O terceiro caso se explica pelo fato de a região ter uma forte base exportadora de soja e outros produtos agroindustriais.

Considerando o comportamento I de Moran global, é possível verificar que houve um aumento da autocorrelação espacial da variável de interesse entre 2008 e 2010, período no qual se registraram taxas positivas de crescimento econômico e baixo nível de desemprego no Estado do Rio Grande do Sul. A queda na correlação espacial verificada posterior a 2010 pode ter sido provocada pela menor atividade econômica no Estado. 
Figura 1: Clusters espaciais de nascimento de empresas, 2007 e 2013

(a) 2007

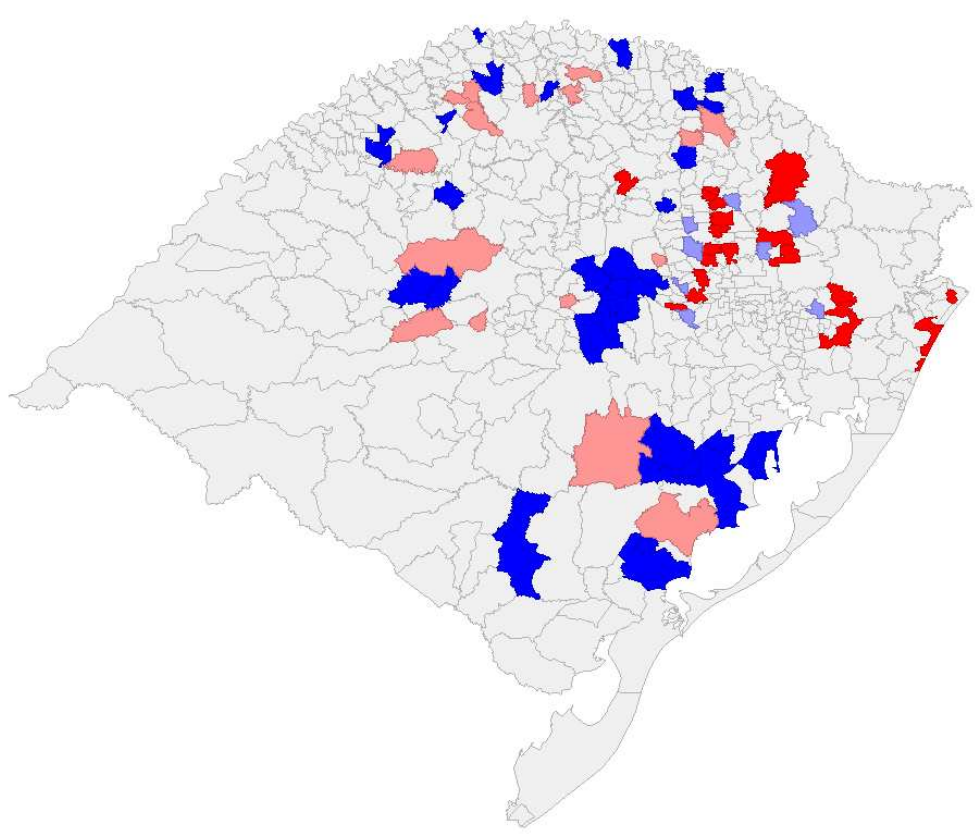

(b) 2013

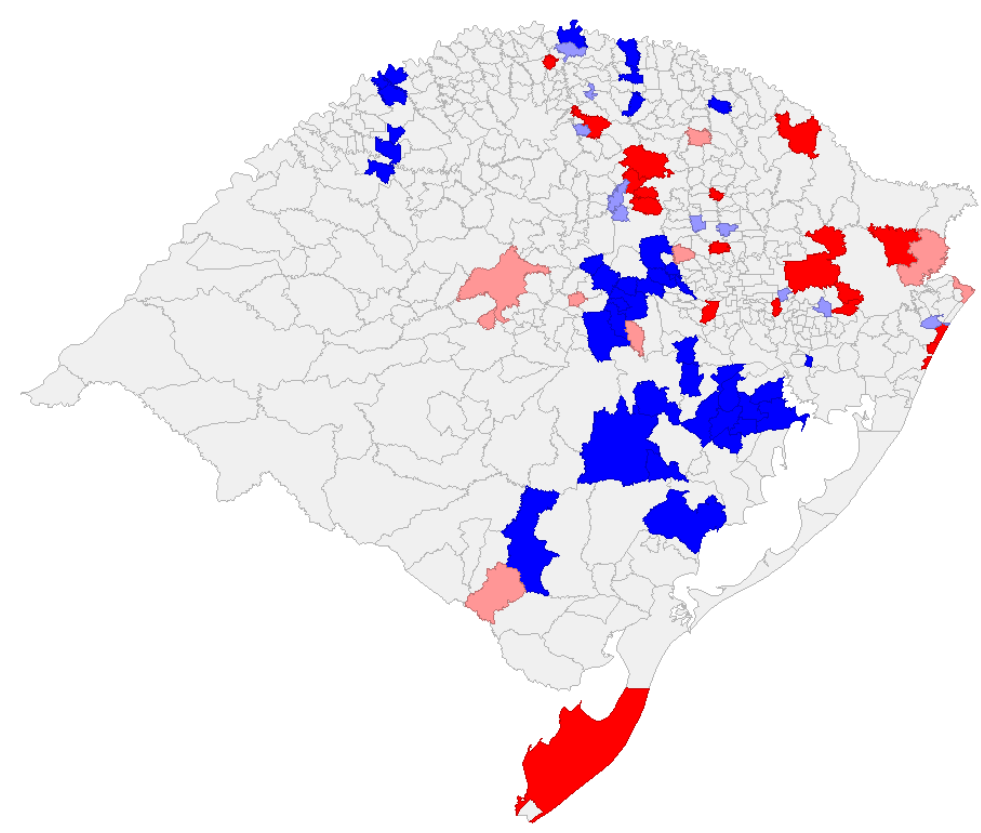
\begin{tabular}{|l|l|l|l|l|l|}
\hline Legenda: & Não significante & Alto-Alto & Baixo-Baixo & Baixo-Alto & Alto-Baixo \\
\hline
\end{tabular} Fonte: Elaboração própria a partir dos resultados da pesquisa. 


\subsection{Modelo de Painel Espacial}

Conforme a sugestão de Almeida (2012), antes de se estimar o modelo de painel espacial, deve estimar-se o modelo em painel padrão, isto é, pooling, efeitos fixos e efeitos aleatórios, em função dos efeitos não observados originados na heterogeneidade individual. Na sequência, após ser escolhido o melhor desses modelos, procede-se à estimação dos modelos de painel espacial, o spatial autoregressive model (SAR) e o spatial error model (SEM). A seguir, uma vez efetuada a escolha de um desses dois modelos, em caso do modelo SAR representar melhor o comportamento dos dados, são calculados os efeitos diretos e indiretos, com a finalidade de avaliar a dimensão do transbordamento espacial e estimar sua importância no efeito total.

Os três modelos em painel padrão foram estimados pelo método MQO. Como se pode verificar na Tabela 5, a estimação do modelo pooling desconsidera os efeitos individuais não observados e evidencia a significância estatística da maioria das variáveis explicativas, mesmo que, no caso de algumas destas, seja contrariado a direção do efeito conforme a expectativa expressa na Tabela 3. Por exemplo, esperava-se que a maior densidade populacional existente nas aglomerações produtivas pudesse afetar de forma positiva o nascimento de empresas, mas o resultado da estimação por meio do modelo pooling verificou o contrário. Algo semelhante acabou ocorrendo com a variável emprego não qualificado e a variável que especifica a participação da atividade do setor da indústria no valor adicionado bruto.

O teste LM, denominado prova de Breusch-Pagan, foi utilizado para verificar a presença dos efeitos individuais não observados quando avaliado o modelo pooling. Ao contrapor o modelo pooling ao modelo de efeitos aleatórios, a hipótese nula favorece ao modelo pooling o qual não especifica os efeitos individuais não observados. O resultado do teste apontou para a rejeição da hipótese nula, ou seja, rejeitou-se que a variância dos resíduos devido aos efeitos individuais é igual à zero. Na sequência, o teste de Hausman possibilitou, ao confrontar os resultados do modelo de efeitos fixos ao modelo de efeitos aleatórios, a escolha da hipótese alternativa em favor do modelo de efeitos fixos.

Havendo verificado a presença de autocorrelação espacial do nascimento de empresas por meio do I de Moran e do LISA, procede-se a estabelecer a dimensão do transbordamento espacial. Para tanto, leva-se em consideração o modelo de efeitos fixos, que é, como acabamos de mostrar, aquele que melhor representa o efeito das variáveis não observadas no comportamento do nascimento de empresas.

A partir do método de máxima verossimilhança, estima-se o modelo de autorregressão espacial (SAR) e o modelo de erros defasados espacialmente (SEM), os quais identificam a dimensão dos efeitos autorregressivos da variável dependente defasada no espaço e dos choques aleatórios espaciais por causa de variáveis omitidas sobre o nascimento de empresas. Esses dois modelos levam em consideração a matriz de contiguidade do tipo Queen. Nos modelos em painel há a necessidade de que a matriz de pesos espaciais seja simétrica. Isso impossibilita o uso de matrizes do tipo " $k$ vizinhos mais próximos". Foi feito um teste de sensibilidade comparando os valores dos parâmetros com uma matriz do tipo Rook. Os resultados desse teste estão no Apêndice A.1.

Na Tabela 6, são apresentados o coeficiente $\rho$, que mede o efeito autorre- 
Tabela 5: Resultados dos modelos estimados: pooling, efeito fixo e efeito aleatório (variável dependente: NascsTrab)

\begin{tabular}{|c|c|c|c|}
\hline Variáveis & $\mid \begin{array}{c}\text { Modelo MQO } \\
\text { (Pooling) }\end{array}$ & $\begin{array}{c}\text { Modelo de Efeitos } \\
\text { Aleatórios }\end{array}$ & $\begin{array}{c}\text { Modelo de Efeitos } \\
\text { Fixos }\end{array}$ \\
\hline (Intercept) & $\begin{array}{l}-6,7338^{* * *} \\
(0,00085311)\end{array}$ & $\begin{array}{l}-2,8322^{* *} \\
(0,0010278)\end{array}$ & \\
\hline DenPopr & $\begin{array}{c}-0,00011072 \\
(4,5788 E-06)\end{array}$ & $\begin{array}{c}0,0017157 \\
(7,66406 E-06)\end{array}$ & $\begin{array}{l}-0,48479^{*} \\
(0,0001978)\end{array}$ \\
\hline EmpNQual & $\begin{array}{c}2,5627^{* * *} \\
(0,00039017)\end{array}$ & $\begin{array}{c}2,26321^{* * *} \\
(0,000531798)\end{array}$ & $\begin{array}{c}0,71833 \\
(0,00080396)\end{array}$ \\
\hline PIBpcr & $\begin{array}{c}0,020064 \\
(4,8748 E-06)\end{array}$ & $\begin{array}{l}0,0175288^{*} \\
(7,1068 E-06)\end{array}$ & $\begin{array}{c}0,015757 \\
(0,000011876)\end{array}$ \\
\hline PocupPEA & $\begin{array}{c}12,509^{* * *} \\
(0,00039004)\end{array}$ & $\begin{array}{c}12,812^{* * *} \\
(0,00054)\end{array}$ & $\begin{array}{c}11,878^{* * *} \\
(0,00098322)\end{array}$ \\
\hline Vpop3a & $\begin{array}{c}8,3363^{* * *} \\
(0,00083022)\end{array}$ & $\begin{array}{c}4,6365^{* * *} \\
(0,00099334)\end{array}$ & $\begin{array}{c}0,80133 \\
(0,0012663) \\
\end{array}$ \\
\hline TamEmp & $\begin{array}{l}-0,32615^{* * *} \\
(8,4398 E-06)\end{array}$ & $\begin{array}{l}-0,32244^{* * *} \\
(0,000011673)\end{array}$ & $\begin{array}{l}-0,30323^{* * *} \\
(0,000017988)\end{array}$ \\
\hline IndVab & $\begin{array}{l}-1,0801^{* * *} \\
(0,00021446)\end{array}$ & $\begin{array}{c}-0,7858^{*} \\
(0,00031647)\end{array}$ & $\begin{array}{c}-0,0981 \\
(0,00055569)\end{array}$ \\
\hline VPocupPEA & $\begin{array}{c}1,4341 \\
(0,00017344)\end{array}$ & $\begin{array}{c}1,3383 \\
(0,00014849)\end{array}$ & $\begin{array}{c}1,3127^{* * *} \\
(0,00015349)\end{array}$ \\
\hline MatrESPop & $\begin{array}{c}0,0022203 \\
(1,5539 E-06)\end{array}$ & $\begin{array}{c}0,0023623 \\
(2,3826 E-06) \\
\end{array}$ & $\begin{array}{c}0,0025893 \\
(4,6666 E-06)\end{array}$ \\
\hline $\mathrm{R}^{2}$ & 0,5219 & 0,521903 & 0,5895 \\
\hline $\begin{array}{l}\text { Teste Breusch-Pagan } \\
\text { Teste de Hausman }\end{array}$ & \multicolumn{3}{|c|}{$\begin{array}{l}\text { Chiq }=32,606 \text { p Value } 2,2 \text { e-16 } \\
\text { Chiq }=44,483 \\
\text { p-value } 0,00000115\end{array}$} \\
\hline
\end{tabular}

Fonte: Elaboração própria a partir dos resultados da pesquisa.

Nota: ${ }^{*}, * * * *$ denotam significância a $10 \%, 5 \%$ e $1 \%$ respectivamente; erro padrão entre parênteses.

gressivo espacial do nascimento de empresas, e o coeficiente $\lambda$, que mede o efeito dos erros defasados espacialmente. Como se observa, ambos os coeficientes resultaram estatisticamente significativos, evidenciando, dessa maneira, o impacto positivo sobre a variável de interesse no município $i$ provocado, tanto pelo aumento no nascimento de empresas nos municípios vizinhos $j$, quanto pelos choques aleatórios ocorridos nos municípios vizinhos $j$. No entanto, embora se confirme a relação de causalidade positiva e se aponte para a significância estatística de ambas as variáveis, os coeficientes resultaram baixos: 0,045744 para o coeficiente da autorregressão espacial; e, 0,048356 para o choque aleatório espacial. O LISA contribui ao entendimento de tal situação, uma vez que a formação de clusters de municípios com alto nascimento de empresas aparece de forma tênue no mapa do Rio Grande do Sul.

O modelo também evidencia que as variáveis População Ocupada em relação à PEA (PocupPEA), a variação da População Ocupada em relação à PEA (VPocupPEA) e o Tamanho das Empresas (TamEmp) resultaram estatisticamente significativas, e corresponderam à expectativa a seu respeito, isto é, as primeiras duas afetam de forma positiva o nascimento de empresas e a terceira indica que quanto menor o tamanho médio das empresas, maior é o número de nascimento de empresas. Além disso, esses efeitos estão de acordo com o modelo proposto por Audretsch \& Fritsch (1993), o qual destaca o impacto positivo das aglomerações de pessoas sobre o nascimento de empresas, bem como, a relação negativa entre o tamanho médio e o nascimento de empresas 
de acordo à abordagem do mercado de trabalho.

Tabela 6: Estimativas dos coeficientes dos modelos de efeitos fixos com dependência espacial, 2007-2013

\begin{tabular}{c|c|c}
\hline Variáveis & SAR & SEM \\
\hline DenPopr & $\begin{array}{c}-0,4835239^{* *} \\
(0,000182687)\end{array}$ & $\begin{array}{c}-0,4783312^{* *} \\
(0,000182848)\end{array}$ \\
\hline EmpNQual & $\begin{array}{c}0,7435871 \\
(0,000742552)\end{array}$ & $\begin{array}{c}0,7235587 \\
(0,000744122)\end{array}$ \\
\hline PIBpcr & $\begin{array}{c}0,0151184 \\
(1,09728 E-05)\end{array}$ & $\begin{array}{c}0,016243 \\
(1,10128 E-05)\end{array}$ \\
\hline PocupPEA & $\begin{array}{c}11,5982999^{* * *} \\
(0,000917681)\end{array}$ & $\begin{array}{c}11,8887675^{* * *} \\
(0,000922364)\end{array}$ \\
\hline Vpop3a & $\begin{array}{c}0,8802852 \\
(0,001169735)\end{array}$ & $\begin{array}{c}0,8804216 \\
(0,001172257)\end{array}$ \\
\hline TamEmp & $\begin{array}{c}-0,2995494^{* * *} \\
(0,0000166861)\end{array}$ & $\begin{array}{c}-0,3025635^{* * *} \\
(1,67176 E-05)\end{array}$ \\
\hline IndVab & $\begin{array}{c}-0,0887061 \\
(0,000513213)\end{array}$ & $\begin{array}{c}-0,0947092 \\
(0,000514316)\end{array}$ \\
\hline VPocupPEA & $1,3138439^{* * *}$ & $\begin{array}{c}1,3053683^{* * *} \\
(0,000141766)\end{array}$ \\
\hline MatrESPop & 0,0024652 & $0,00211921)$ \\
$(2,4652 E-06)$ & $(4,3061 E-06)$ \\
\hline$\rho$ & $0,045744^{*}$ & \\
\hline$\lambda$ & $(0,020876)$ & \\
\hline AIC & $-17622,38$ & $-17622,53$ \\
\hline BIC & $-14503,07$ & $-14503,22$ \\
\hline
\end{tabular}

Fonte: Elaboração própria a partir dos resultados da pesquisa.

Nota: ${ }^{*},{ }^{* *},{ }^{* * *}$ denotam significância a $10 \%, 5 \%$ e $1 \%$ respectivamente; erro padrão entre parênteses.

Embora a variável densidade populacional seja significativa, esperava-se uma relação positiva entre esta e o nascimento de empresas, resultado que acabou não acontecendo. Outras variáveis, como a taxa de variação da renda dos municípios, a qualidade da mão de obra, a industrialização e o número de matrículas no ensino superior por município, não foram estatisticamente significativas.

A escolha entre o modelo SAR e o modelo SEM foi definida pelos critérios de informação de Akaike e Bayesiano (AIC e BIC). Como podem ser observados os valores correspondentes ao modelo SEM apontaram para o melhor ajuste. No entanto, como os valores dos critérios de informação foram muito próximos, resulta oportuno referirmos aos efeitos transbordamento das variáveis independentes por meio do modelo SAR, como pode ser visto na Tabela 7. O seu cálculo permite distinguir o efeito de transbordamento espacial das variáveis independentes sobre o nascimento de empresas.

Esses efeitos de transbordamento decorrem do fato de que nos modelos de econometria espacial as unidades espaciais (nesse caso municípios) são conectadas pela matriz de pesos. Com isso, uma mudança em uma variável exógena em um determinado município impacta na variável endógena do próprio e de 
outros municípios. Em termos mais técnicos, a matriz de derivativas parciais dos efeitos das variáveis exógenas sobre a endógena, diferentemente do modelo não espacial, possui elementos não nulos fora da diagonal principal. Este resultado decorre da expressão $(I-\rho W)^{-1}$ presente na forma reduzida do modelo da Equação 6 (Golgher (2015), p. 47-72).

Le Sage \& Pace (2009) definem o efeito direto indireto e total da seguinte forma: o efeito direto é a média da diagonal principal da matriz de derivativas parciais; o efeito indireto é a média das somas dos elementos não diagonais em cada linha ou coluna da matriz; e o efeito total é soma do efeito direto e indireto. A decomposição desses efeitos foi realizada por meio do software R, usando o pacote SPLM (Econometric Models for Spatial Panel Data).

Tabela 7: Impactos diretos e indiretos no modelo SAR

\begin{tabular}{c|c|c|c}
\hline Variáveis & Efeito Direto & Efeito Indireto & Efeito Total \\
\hline DenPopr & $-0,4835$ & $-0,0232$ & $-0,5067$ \\
PocupPEA & 11,5983 & 0,5560 & 12,1543 \\
TamEmp & $-0,2995$ & $-0,0144$ & $-0,3139$ \\
VPocupPEA & 1,3138 & 0,0630 & 1,3768 \\
\hline
\end{tabular}

Fonte: Elaboração própria a partir dos resultados da pesquisa.

Nota: foram consideradas apenas as variáveis estatisticamente significativas.

Das quatro variáveis significativas da Tabela 7 , um aumento da proporção da população ocupada em relação à população economicamente ativa (PocupPEA) e um aumento da mesma (VPocupPEA) influenciam positivamente a formação de novas empresas nos municípios. Por outro lado, aumentos da densidade demográfica (DenPopr) e do tamanho médio das empresas (Ta$\mathrm{mEmp}$ ) influenciam negativamente o nascimento de novas empresas. Esses efeitos do desemprego sobre a formação de novas empresas vão ao encontro dos resultados encontrados por Menezes (2011). Por outro lado, contrariam a ideia do empreendedorismo por necessidade. No entanto, é preciso considerar que neste estudo não foram consideradas as microempresas individuais, que, como foi visto anteriormente, são as que mais crescem em momentos de dificuldades econômicas.

Tomando como exemplo a variável PocupPEA para mostrar o tamanho dos impactos, pode-se afirmar que o aumento de uma unidade na proporção "população ocupada/população economicamente ativa" está associado ao aumento total de $0,01215(12,15 / 1000)$ na proporção "novas empresas/população economicamente ativa". Utilizando os valores médios das variáveis da Tabela 2 , esses resultados podem ser interpretados da seguinte forma: se a PocupPEA for multiplicada por 1,1 , passando de 0,2023 para $0,2225\left(0,2023^{\star} 1,1=0,2225\right)$, o NascTrab será multiplicado por 1,01215 e passa de 4,8084 para $4,8642\left(4,8084^{\star} 1,0116=4,8642\right)$. Desse efeito total, em torno de $95 \%$ do mesmo referem-se ao impacto direto e $5 \%$ de impacto indireto. O impacto direto, como já foi visto, é o efeito da variável exógena em questão no município sobre a variável endógena no próprio município e o impacto indireto é o efeito sobre a variável endógena em municípios vizinhos.

Leitura semelhante pode ser feita para as demais variáveis estatisticamente significativas, densidade populacional, tamanho médio dos estabelecimentos e a variação da população ocupada. Considerando as quatro variáveis signifi- 
cativas, conclui-se que o efeito transbordamento (indireto) ficou próximo de $5 \%$ do total.

Embora os indicadores da Análise Exploratória de Dados Espaciais obtidos e os resultados do modelo de painel espacial evidenciem a existência de efeitos espaciais sobre o nascimento de empresas, esses foram pequenos. Provavelmente a causa para tal comportamento se deva ao número ainda baixo de aglomerações produtivas identificadas e distribuídas ao longo do território do Rio Grande do Sul. No entanto, os resultados das variáveis que são estatisticamente significativas estão de acordo com os resultados encontrados por Audretsch \& Fritsch (1993) para o caso alemão.

\section{Conclusões}

Este trabalho teve por objetivo estudar, a partir de uma abordagem espacial, o nascimento de empresas nos municípios do Rio Grande do Sul no período de 2007-2013. Por meio do Índice de Moran foi possível verificar a existência de correlação espacial positiva na variável de interesse nascimento de empresas nos municípios. Isso significa dizer que essa variável não se distribui de forma aleatória ou que existe dependência espacial global positiva, indicando que municípios com valor alto estão cercados de municípios também com valor alto. O mesmo vale para valores baixos.

$\mathrm{Na}$ análise de dependência espacial local, foi possível identificar clusters espaciais, envolvendo um número de municípios relativamente baixo. Os clusters do tipo alto-alto predominaram na parte norte do Estado e os do tipo baixo-baixo na parte sul. Mais especificamente, os clusters do tipo alto-alto foram encontrados principalmente nos municípios localizados na mesorregião Nordeste Rio-grandense e os clusters do tipo baixo-baixo especialmente na mesorregião Sudeste Rio-grandense. O bom desempenho dos municípios da região Nordeste em termos de formação de novas empresas pode ser explicado pela proximidade ao parque industrial existente no município de Caxias do Sul. Por outro lado, o baixo desempenho verificado na região Sudeste se justifica por essa região ser dependente do setor primário, com solos de baixa fertilidade, e com histórico de baixo desenvolvimento. Na região metropolitana de Porto Alegre, não se observou a formação de clusters, indicando heterogeneidade dos municípios que ali estão em termos de formação de novas empresas.

No ano final da análise, foram identificados alguns clusters do tipo altoalto nos municípios praianos do Litoral Norte do Estado. Esse resultado pode ser explicado pelo forte dinamismo populacional que essa região vem apresentando nos últimos anos. Entre 2001 e 2016, essa região teve um aumento populacional quatro vezes maior que a média do Rio Grande do Sul.

Diversas variáveis representativas das aglomerações produtivas foram submetidas a teste com a finalidade de verificar os seus impactos sobre o nascimento de empresas. Em relação a esses resultados, pode-se dizer que a proporção da população ocupada e o crescimento da população ocupada impactam positivamente a formação de novas empresas nos municípios. Por outro lado, o tamanho médio das empresas e a densidade populacional impactam negativamente a formação de novas empresas. Esses resultados indicam que a dinâmica empreendedora no período analisado está diretamente associada à dinâmica do mercado de trabalho. Essa dinâmica, por sua vez, não se deu nos 
locais de maior densidade populacional e na presença de grandes empresas, variáveis típicas de grandes aglomerações. Conclui-se, portanto, que o bom desempenho em termos de nascimento de empresas esteve associado principalmente às cidades de tamanho médio e localizadas na parte norte do Estado, particularmente a região Sudeste onde se encontra a cidade de Caxias do Sul.

De forma adicional, foram calculados os efeitos de transbordamento espacial do nascimento de empresas. Os resultados indicaram que do impacto total das variáveis, em torno de $95 \%$ do mesmo refere-se ao impacto direto e $5 \%$ de impacto indireto. Como é o impacto indireto que mostra os efeitos de transbordamento, conclui-se que os mesmos, embora tenham sido estatisticamente significativos, foram relativamente pequenos.

Espera-se que os resultados desta pesquisa contribuam para a formulação de políticas públicas visando estimular a formação de empresas nos municípios. Esse é um tema de fundamental importância para o desenvolvimento regional e que carece de estudos econômicos robustos. Como existem diferenças regionais em termos de tamanho das cidades e estruturas produtivas, é importante avançar em pesquisas mais desagregadas regionalmente. Também, dado que os setores possuem diferentes fatores locacionais, é importante pesquisar o nascimento de empresas por diferentes atividades produtivas.

\section{Referências Bibliográficas}

Aghion, P. \& Howitt, P. (1998), Endogenous growth theory, MIT Press.

Almeida, E. (2012), Econometria espacial, primeira edição, Editora Alínea.

Almeida, E., Mattos, R. \& Souza, D. (2014), Efeitos espaciais e elasticidades da demanda residencial de eletricidade no Brasil, in 'Seminários Programa de Pós-graduação em Economia', number visitado em setembro de 2017, UFJF.

URL: http://www.ufjf.br/seminarios_ppge/files/2014/06/Efeitos-espaciais-eelasticidades-da-demanda-residencial-de-eletricidade-no-Brasil.pdf

Arbia, G. (2014), A primer for spatial econometrics, Palgrave Texts in Econometrics, Palgrave Macmillan.

Audia, A. P. G. \& Sorenson, O. (2000), 'The social structure of entrepreneurial activity: geographic concentration of footwear production in the United States', American Journal of Sociology 106(2), 424-62.

Audretsch, D. B., Bonte, W. \& Keilbach, M. (2008), 'Entrepreneurship capital and its impact on knowledge diffusion and economic performance', Journal of Business Venturing 23, 687-698.

Audretsch, D. \& Fritsch, I. (1993), 'The geography of firm births in Germany', Regional Studies 28(4), 359-365.

C, A. \& Acs, A. (2002), 'The determinants of regional variation in new firm formation', Regional Studies 36, 33-45.

Canever, M., Menezes, G. \& Kohls, V. (2011), Taxa de formação de empresas no Rio Grande do Sul: deslocamentos espaciais e relação com o crescimento econômico, in 'In Anais da II Conferência do Desenvolvimento/Code'. 
Carraro, A. \& Canever, M. (2012), 'Enterprise creation and economic recovery: the case of Rio Grande do Sul', CEPAL Review (108), 127-139.

Doring, T. \& Schnellenbach, J. (2004), What do we know about geographical knowledge spillovers and regional growth?, in 'A survey of the literature', number Research Notes, n. 14, Econstor.

Evans, D. \& Jovanovic, B. (1989), 'An estimated model of entrepreneurial choice under liquidity constraints', Journal of Political Economy 97(4), 808827.

Fritsch, M. (2011), 'New business formation and regional development, a survey and assessment of the evidence', DIW Berlin May.

Golgher, A. (2015), Introdução à econometria espacial, primeira edição edn, Paco Editorial.

Johnson, D. \& Parker, S. (1996), 'Spatial variations in the determinants and effects of firm births and deaths', Regional Studies 30(7), 679-688.

Keeble, D., Walker, S. \& Robson, M. (1993), New firm formation and small business growth in the United Kingdom: spatial and temporal variations and determinants, in 'Research Series', number 15, Department of Employment, London.

Krugman, P. (1991), 'Increasing returns and economic geography', Journal of Political Economy 99(3).

Le Sage, J. P. \& Pace, R. K. (2009), Introduction to spatial econometrics, CRC Press.

Lee, J. (2001), Entrepreneurship and business development among African Americans, Koreans, and Jews: exploring some structural diferences, Philadelphia.

Lee, S. Y., Florida, R. \& Acs, Z. (2004), 'Creativity and entrepreneurship: a regional analysis of new firm frmation', Regional Studies 38(8), 879-891.

Levratto, N. (2015), 'Imitation or opposition? A focus on neighbouring effects at the local level in the business creation process', Journal of Innovation Economics \& Management (17), 65-192.

Levratto, N. \& Carré, D. (2014), Does firm creation on local context? A focus on the neighbouring effects (provisional version), in 'EconomiX', University of Paris, Ouest, Nanterre, La Défense, Centre dÉtudes de lÉmploi, Kedge Business School, Marseille.

Lopez-Garcia, P. \& Puente, S. (2006), Business demography in Spain: determinants of firm survival, in 'Documentos de trabajo', number 0608, Banco de España.

McCANN, P. (2013), Modern urban and regional economics, second edition edn, Oxford University Press.

Menezes, G. (2011), Dois ensaios sobre taxa de formação de empresas: uma análise para os municípios gaúchos, $\mathrm{PhD}$ thesis, Dissertação de mestrado apresentada ao Programa de Pós-graduação em Organizações e Mercados da Universidade Federal de Pelotas. Pelotas. 
Menezes, G. (2015), Ensaios sobre economia do empreendorismo, PhD thesis, Porto Alegre, UFRGS.

Olejnik, A. (2014), 'An empirical study of productivity growth in EU28 Spatial panel analysis', Comparative Economic Research 17(4).

Plummer, L. A. (2010), 'Spatial dependence in entrepreneurship research: challenges and methods', Organizational Research Methods 13(1), 146-175.

Reynolds, P. M. B. \& Maki, W. (1992), Regional characteristics affecting business volatility in the United States, 1980-4, London.

Rezende, A., Campolina, B. \& Paixão, A. (2012), 'Clusterização e localização da indústria de transformação no Brasil entre 1994 e 2009', Revista Econômica do Nordeste 43(4).

Ross, A., Adams, J. \& Crossan, K. (2015), 'Entrepreneurship and the spatial context: a panel data study into regional determinants of small growing firms in Scotland', Local Economy 30(6), 672-688.

SEBRAE (2017), Relatório especial: o empreendedorismo e o mercado de trabalho, Estudos e Pesquisas. 


\section{Apêndice A}

Tabela A.1: Análise de sensibilidade dos parâmetros dos modelos a diferentes tipos de matrizes de pesos espacias

\begin{tabular}{c|c|c}
\hline Variáveis & $\begin{array}{c}\text { Modelo de Efeitos Fixos } \\
\text { Modelo SAR }\end{array}$ & $\begin{array}{c}\text { Modelo de Efeitos Fixos } \\
\text { Modelo SEM }\end{array}$ \\
\hline DenPop & 1,0012 & 1,0033 \\
EmpNQual & 1,0042 & 0,9954 \\
PIBpcr & 0,9968 & 0,9993 \\
PocupPEA & 0,9991 & 1,0012 \\
Vpop3a & 0,9681 & 0,9991 \\
TamEmp & 0,9996 & 1,0009 \\
IndVab & 0,9850 & 0,9960 \\
VPocupPEA & 0,9992 & 0,9988 \\
MatrESPop & 0,9918 & 0,9854 \\
\hline
\end{tabular}

Fonte: resultados da pesquisa.

Nota: Os valores referem-se aos valores dos coeficientes obtidos com a matriz

alternativa Rook dividido pelos valores dos coeficientes obtidos com a matriz usada Queen. 


\section{Apêndice B}

Tabela B.1: Lista dos municípios pertencentes a clusters do tipo alto-alto em 2007 e em 2013

\begin{tabular}{|c|c|c|}
\hline 2007 & 2013 & 2007 e 2013 \\
\hline $\begin{array}{c}\text { Antônio Prado } \\
\text { Arroio do Meio } \\
\text { Canela } \\
\text { Capão da Canoa } \\
\text { Cotiporã } \\
\text { Dois Lajeados } \\
\text { Dom Pedro de Alcântara } \\
\text { Encantado } \\
\text { Ernestina } \\
\text { Flores da Cunha } \\
\text { Ibirapuitã } \\
\text { Imbé } \\
\text { Jaquirana } \\
\text { Lagoa Vermelha } \\
\text { Muitos Capões } \\
\text { Nova Bassano } \\
\text { Paraí } \\
\text { São Domingos do Sul } \\
\text { Santa Clara do Sul } \\
\text { Taquara } \\
\text { Terra de Areia } \\
\text { Três Cachoeiras } \\
\text { Três Coroas } \\
\text { Vanini } \\
\text { Venâncio Aires } \\
\text { Vespasiano Correa } \\
\text { Vista Alegre do Prata } \\
\text { Xangri-lá }\end{array}$ & $\begin{array}{c}\text { Bom Princípio } \\
\text { Canela } \\
\text { Capão da Canoa } \\
\text { Caxias do Sul } \\
\text { Cristal do Sul } \\
\text { Dois Lajeados } \\
\text { Ernestina } \\
\text { Estrela } \\
\text { Humaitá } \\
\text { Ibirapuitã } \\
\text { Imbé } \\
\text { Jaquirana } \\
\text { Nicolau Vergueiro } \\
\text { Passo Fundo } \\
\text { São Domingos do Sul } \\
\text { Santa Vitória do Palmar } \\
\text { Sarandi } \\
\text { Três Coroas } \\
\text { Xangri-lá }\end{array}$ & $\begin{array}{c}\text { Canela } \\
\text { Capão da Canoa } \\
\text { Dois Lajeados } \\
\text { Ernestina } \\
\text { Ibirapuitã } \\
\text { Imbé } \\
\text { Jaquirana } \\
\text { São Domingos do Sul } \\
\text { Três Coroas } \\
\text { Xangri-lá }\end{array}$ \\
\hline
\end{tabular}

Fonte: Resultados da pesquisa. 
